\title{
A model for the design of computer integrated manufacturing systems: Identification of information requirements of decision makers
}

Rasmussen, Jens

Published in:

International Journal of Industrial Ergonomics

Publication date:

1990

Document Version

Peer reviewed version

Link back to DTU Orbit

Citation (APA):

Rasmussen, J. (1990). A model for the design of computer integrated manufacturing systems: Identification of information requirements of decision makers. International Journal of Industrial Ergonomics, 5(1), 5-16.

\section{General rights}

Copyright and moral rights for the publications made accessible in the public portal are retained by the authors and/or other copyright owners and it is a condition of accessing publications that users recognise and abide by the legal requirements associated with these rights.

- Users may download and print one copy of any publication from the public portal for the purpose of private study or research.

- You may not further distribute the material or use it for any profit-making activity or commercial gain

- You may freely distribute the URL identifying the publication in the public portal

If you believe that this document breaches copyright please contact us providing details, and we will remove access to the work immediately and investigate your claim 


\title{
MODELS FOR DESIGN OF COMPUTER INTEGRATED MANUFACTURING SYSTEMS: IDENTIFICATION OF INFORMATION REQUIREMENTS OF DECISION MAKERS ${ }^{1}$
}

\author{
Jens Rasmussen \\ Technical University, Copenhagen \& Risø National Laboratory
}

\begin{abstract}
A predominant interest in recent design research has been the development of a general model of the design process to formulate a framework within which support systems based on modern information technology can be developed. Similarly, for manufacturing systems, advanced information systems are developed to support production planning and control processes as they are found in the present organizations. In this case, the result has been the evolution of "islands of automation" and in the CIM literature, integration is widely discussed in terms of standardization of communication protocols and compatibility of data bases.

It is, however, a question whether traditional models of work process or task procedures are suited for design of advanced information systems such as integrated manufacturing systems. Modern technology and the rapid succession of designs, materials and processes require flexible systems; tasks and functions of people are not stable, and introduction of advanced tools will influence work procedures, roles of people and organizational structures.

Design of integrated information systems should neither be based on normative work procedures, nor on past role allocations. Design should rather aim at creating a resource envelope within which people can adapt their work strategies to the current requirements and personal preferences without loosing support from the system. This requirement implies that for design purposes, models of procedures and processes should be replaced by structural models of means and ends in the work domain, of the decision tasks in general, domain independent terms, together with the effective decision strategies, and of the human resources and preferences.

The paper presents an analysis of a number of actual engineering design projects. The design processes and production planning in these cases involve decisions within several different work domains which are normally known in detail by different people. The cases are used to illustrate how an explicit representation of the means-ends relations of the work domain can be used to identify the information requirements of the decision makers involved, the role of the different decision makers, and their interaction. In addition, it is shown how this representation is useful to analyze the propagation of changes through a system, when resources are changed, by introduction of new tools or change of staffing.
\end{abstract}

\section{INTRODUCTION}

The topic of the paper is a discussion of conceptual models suited for design of work stations for advanced manufacturing systems. In spite of much discussion of integrated manufacturing systems, most effort has been spent on development of advanced, but separate systems for computer aided design, flexible manufacturing, etc., and the integrating efforts have been focused on integration of computer systems and the resulting compatibility problems (Lenau and Alting, 1988; Bohn and Jaikumar, 1984).

\footnotetext{
${ }^{1}$ Invited Conference Address; First International Conference on Ergonomics of Advanced Manufacturing and Hybrid Automated Systems; Louisville, Kentucky, USA; August 1988. In: International Journal of Industrial Ergonomics, Vol.5, No. 1, pp.5-16, January, 1990.
} 
In consequence, models of activities in advanced manufacturing systems have been related to separate functions within the total system. Such models are important for optimization of the local functionality but, as has frequently been argued, tend to result in 'islands of automation' which are difficult to coordinate and integrate. A house is not designed bottom-up integrating elements of optimal functionality, neither can an integrated engineering system be created by bottom-up integration of functionally optimal element. An overall model of an adequate information system architecture is needed in both cases.

What is such a model of system architecture like? The structure and concepts required for a model depend entirely on the intended use of the model; whether it is intended for hypothesis generation for basic research, for teaching engineering skills, or for design of work stations for professional users. In modern systems, information technology takes care of most well-structured and frequently used functions and, consequently, the prominent role of human agents will be to coordinate the various specialized functions and to adapt creatively to the variability of work requirements which is a predominant feature of modern work conditions. In a rapidly changing technology, the human role is to act as a high-level supervisor, to adapt the integrated performance to the varying system goals and performance limits.

In this situation, design of the human work interface cannot be based on normative work procedures. Problem solving, goal evaluation, and planning for a new requirement are intellectual activities for which the procedure adopted by a particular individual in a particular situation cannot be predicted nor can it be controlled by a normative procedure. Analysis of the task and design of support systems must, in stead, take into consideration the different dimensions of a resource envelop around the relevant alternative paths of action. In this way, the individual user will be able to adapt to new requirements and choose a strategy according to the subjective resources and preferences. Such a design will depend on generalizations in terms of effective work strategies from analysis of actual work scenarios, but generalizations should be in terms of situation independent parameters, not in terms of normative task sequences.

Why, then, are procedural models predominantly presented in the literature? As Hubka (1984) notes: "The predominant Centre of interest in recent design research has been the generation of general procedural models. This may be seen from the many models that have been published." This is, as it will be argued below, probably the case because most modelling efforts are spent in university groups to support teaching design competency, not for design of information systems.

\section{FRAMEWORK FOR SYSTEM DESIGN.}

When design is to be based on the concept of an adequate resource envelope in stead of support of a particular normative work procedure, it follows that separate, task independent models are required of: 1.) the work domain, i.e., the space in which the trajectory of the work procedure chosen will unfold, see figure $1 ; 2$.) the users goal structure, i.e., the characteristic decision functions such as analysis and diagnosis, goal evaluation, and planning; and 3.) the users resource profile depending on training and skill determining the criteria behind selection of coping strategy.

The arguments are very similar to Simon's classic discussion of the complexity of the path of an ant in the environment: "Viewed as a geometric figure, the ant's path is irregular, complex, hard to describe. But the complexity is really a complexity in the surface of the beach, not a complexity in the ant." (Compare with figure 1). Simon's example is generalized in the dictum: "A man, viewed as a behaving system, is quite 
simple. The apparent complexity of his behavior is largely a reflection of the complexity of the environment in which he finds himself." Even if, as I have argued elsewhere (Rasmussen, 1974, 1986), man is rather simple in a complex way by having several levels of cognitive control to chose from, the following observation of Simon is particularly relevant for the design of decision support systems in supervisory tasks: "A thinking human being is an adaptive system; his goals define the interface between his inner and outer environments. To the extent that he is effectively adaptive, his behavior will reflect characteristics largely of the outer environment (in the light of his goals) and will reveal only a few limiting properties of his inner environment-the psychological machinery that enables him to think."

\begin{tabular}{|c|c|c|c|c|c|}
\hline $\begin{array}{l}\text { Whole- } \\
\text { Means- } \\
\text { Ends }\end{array}$ & $\begin{array}{l}\text { Total } \\
\text { System }\end{array}$ & $\begin{array}{l}\text { Sub- } \\
\text { System }\end{array}$ & $\begin{array}{l}\text { Function } \\
\text { Unit }\end{array}$ & $\begin{array}{l}\text { Sub-As- } \\
\text { sembly }\end{array}$ & $\begin{array}{l}\text { Com- } \\
\text { ponent }\end{array}$ \\
\hline $\begin{array}{l}\text { Functional } \\
\text { Meaning, Pur- } \\
\text { poses }\end{array}$ & 1 & & & & \\
\hline $\begin{array}{l}\text { Information } \\
\text { Measures }\end{array}$ & $\nabla$ & & & & \\
\hline $\begin{array}{l}\text { General } \\
\text { Functions }\end{array}$ & & & & & \\
\hline $\begin{array}{l}\text { Physical } \\
\text { Processes }\end{array}$ & & & & & $15)$ \\
\hline $\begin{array}{l}\text { Material Form } \\
\text { Configuration }\end{array}$ & & & & $\begin{array}{l}\nabla / \\
(12\end{array}$ & 14 \\
\hline
\end{tabular}

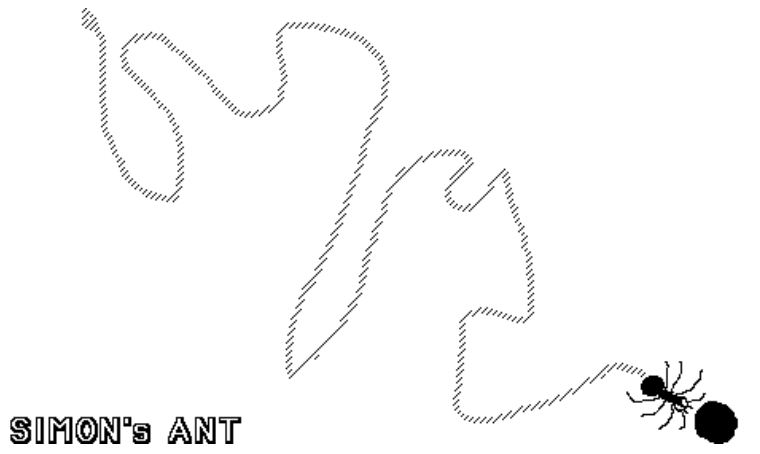

Simon's ant: "Viewed as a geometric figure, the ant's path is irregular, complex, hard to describe. But the complexity is really a complexity in the surface of the beach, not a complexity in the ant."

Figure 1. The figure illustrates the trajectory of the activities of a maintenance technician in the problem space representing a computer system and defined by means-ends and part-whole relations. From a verbal protocol it is found that he approaches the system from several different points of view: as a set of physical components with specific appearance and locations, as different electronic circuits with their physical processes, as computer system functions, as information theoretic relations and, finally, as application programs serving the user's purpose. These views define different levels in a means-ends hierarchy. In addition, he is continuously changing his span of attention, i.e., changing his representation 
along the part-whole dimension. No two trajectories of maintenance of the system are similar, and a procedural model will not be able to capture the variability of real-life performance.

A model framework according to this point of view is described elsewhere (Rasmussen, 1986, 1988), and the key characteristics are reviewed in figure 2. Since the work space representation is used to present the following examples, a short review of its features may be illuminating.

When information systems are intended to support improvisation and adaptation to new requirements, the work domain must be analyzed and represented in task independent terms as a space spanned by means-end and part-whole dimensions (Rasmussen, 1985). These relations are important for analysis of the state of affairs, for setting priorities, and for planning in any work situation involving resource management and adaptation to changing conditions. Decisions, in general, are not based on primary data about the state of affairs and consideration of the ultimate goal. Goals have to be interpreted and concretized to be operational, and primary data must be integrated and generalized before they can be related to goals. For effective support of decision processes, therefore, the substance matter of a work domain should be represented at several levels of abstraction, representing goals and requirements, general functions, physical processes and activities, as well as material resources. Alternatives for action and, consequently, need for decisions are only present if a many-to-many mapping is found between the levels. Furthermore, items of any level (what should be used) can be seen both as a goal (why it is relevant) for a function at a lower level, and as a means for a function at a higher level (how it is realized).

\section{DOMAINS OF WORK ANALYSIS FOR SYSTEMS DESIGN.}

* Problem Space.

Means-Ends/Part-Whole Space; Represents global knowledge base and available alternatives for activities.

* Decision Task.

Identifies the activity in general terms, e.g., diagnosis, goal evaluation, planning.

* Mental Information Processing Strategies.

Description of the effective mental processing strategies which can be used.

* Cognitive Level of Interpretation and Resources.

Identification of the level of expertise of the system user, the competency, and the criteria for selection of strategies which will be used.

* Allocation of Roles to Human Agents.

Description of the role of individuals in terms of window to global problem space and type of activities.

*Structure of the Social Organisation. 
Structure of the co-ordination of the activities of agents; conventions for co-ordinating communication.

Figure 2. A cognitive job analysis of activities in advanced systems, characteristic by discretionary tasks rather than repetitive routines, cannot be based on procedural descriptions. Instead, analysis should be made in different structural domains in order to be able to design work tools and support systems that will offer the user a resource envelope within which he can navigate freely without loosing support.

Goal oriented planning means exploration of means and ends together with selection of adequate resources according to the relevant, often subjective, process criteria. In any planning task involving exploration of a means-ends network, and for which no normative work procedure can be given, it is important that the user can navigate freely in the means-ends network. Any potentially useful function or item in a work context is located in a means-end network and, consequently, can be characterized in terms of 'what' it is, 'why' it can be useful, and 'how' it can be used or implemented irrespective of the actual situation. This in turns implies that its representation in a data base for an integrated work station should include these features in a way that the items can be retrieved from search questions, posed from different point of view. Therefore, integrated systems depend on compatible databases, designed for the intended system, not on co-ordination of an ad-hoc collection of databases designed in isolation.

When navigating in the work domain, it is immediately clear that novices and experts will use different mental strategies. Novices - and experts facing new situations will have to use more or less rational analysis involving consideration of the means-end relationships as well as causal arguments. Routine performance by skilled experts, however, will be based on know-how in terms of associations directly from signs representing familiar situations to stereotypical patterns of actions. For an analytical approach to a problem, different strategies will be available. These strategies will typically require different resource profiles and, consequently, shift in strategy may be used to avoid violation of capacity limits. Such shifts result in a very varied course of a particular decision process depending on very subjective and situation-dependent details. Consequently, no two trajectories in the work domain as shown in figure 1 and the following examples will be similar.

\section{SOME ACTUAL DESIGN PROBLEMS}

To set the stage for a discussion of model requirements when designing advanced manufacturing systems, a couple of actual design tasks are reviewed in this section (see figure 3): 


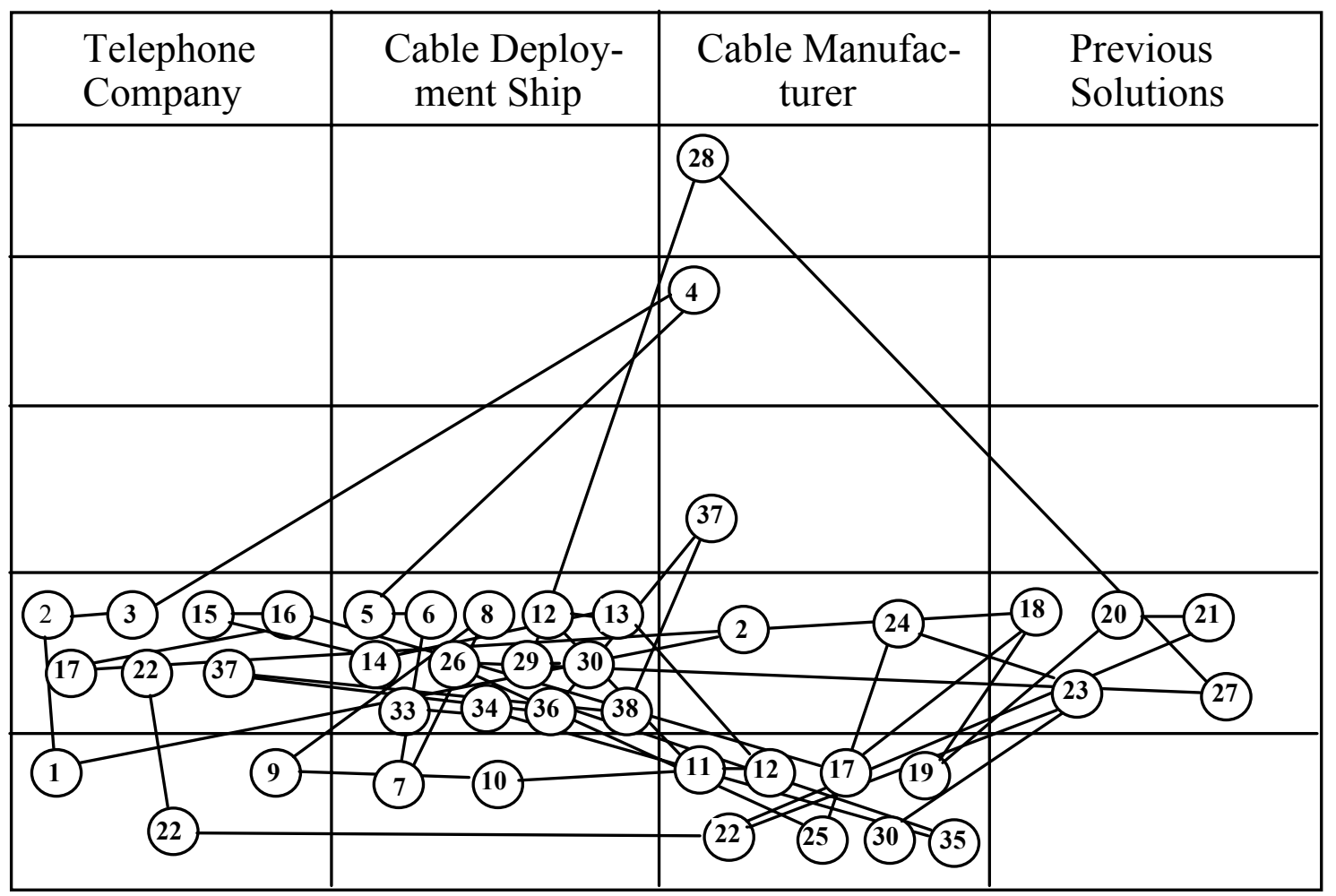

Figure 3. The trajectory of work during design of a cable joint; one of the three actual design tasks discussed in the text. The figure illustrates clearly that the process is not a well-ordered transformation of specifications into a product, but a lengthy iteration among domains which are normally isolated. It is also seen that classic function-form transformation is only a very limited part of the task.

Design of Cable Joint: A telephone company needs a cable joint to be used for assembling under-sea optic-fibre cables and, together with the cable manufacturer, contact is made to a design team at the mechanical engineering institute of a technical university. The functional product requirements are specified, such as the number of light conductors, the predicted cable stress in case the cable is caught by a ship anchor, the deployment equipment and procedure to be used and, finally, the physical-chemical specifications of the sea environment.

Deployment equipment constrains the acceptable external diameter. On the other hand, the predicted low reliability of laser-welding operation at sea, requires room for coils absorbing some spare length of each fibre to enable individual re-welding, which implies need for increased internal diameter of the joint. A completely new design of the mechanical configuration of the joint is therefore necessary in order to find a less space consuming fixture to absorb the specified cable stress. In addition, delicate laser welding operations are required on board the cable deployment ship under rough sea condition. These requirements lead to a complex iteration between form-function condtions for which the cable joint is viewed as 1. part of a under-sea telephone line, 2. an object of a rough sea assembly task, 3. the object of manufacturing processes and finally, 4. as a modification of prior cable joint solutions.

This example illustrates a rather clear-cut and typical design task in which change of one material in an assembly, normally based on a well established design tradition, requires an up-date of the physical design. As it turns out, however, a complete reconsideration is required within several contexts which are known only by different experts, an engineer from the telephone company, the foreman of the assembly team of the cable deployment ship, and the production planner of the cable manufacturer. In the 
design situation, they have to identify the implications for their respective domains for a solution which does not exist and which depend on these implications. Therefore, for a considerable period of the design, the role of the design team is to be mediators in a domain exploration, supported by a number of design proposals, mock-up models, and experiments with part-solutions.

Design of Door Lock: A manufacturer of locks wants to modernize the production facilities by introduction of computer controlled machinery. The increased production accuracy gives the possibility of an update of the lock design with more 'bits' in the lock code. This, in turn, opens the potential for more complex 'integrated lock systems' with key codes grouped for different personnel categories of an organization. This can influence personnel administration and insurance conditions of a customer. In addition, the computer based technology offers a change of the strategy for design of the individual lock system. In the old design, the foreman of the production workshop would choose the set of key codes of a particular lock system from tables on paper forms and simple heuristic rules concerning useful and inadequate combinations. In the new system, the combinatorial space is too large for heuristic design, production planning of particular systems must be based on a mathematical model which, however, can be implemented as a planning program in a portable computer. This, in turn, makes it possible for the lock manufacturer's travelling salesman to plan a particular lock system and choose the relevant code system in direct interaction with a representative from the customer's organization and hand over to the workshop, a complete production specification in form of a program listing for the numerically controlled production equipment.

In this example, the design problem is initiated by introduction of new production equipment, which reflect back on an updated product design which, in turn, give a potential for a different application philosophy in the customer's organization with influence on personnel administration and insurance policy. In addition, the new planning tools, made necessary by the more complex planning context, opens up the possibility of a new role allocation in the manufacturing organization, in which production planning is moved from the workshop floor to the sales department.

Design of Product Accounting Equipment for Retail Chain Shop. In this example, the design problem starts as a classical function-form design task: Design is required of a tool for measuring what is left in a roll of material without unrolling and measuring with a yard-stick. The purpose is to facilitate the annual status accounting which was a considerable problem in a firm with thousands of rolls. As the design process unfolds, details in the design implementation initiates ideas which result in a propagation of potential changes through the organizational structure of the firm. The solution imagined is weighing of the rolls together with a calibration of weight/length relation, followed by a calculation of remaining length of material. Considering all the different designs and shape of roll-cores from different production sources, a correction is needed of the weight measured, i.e., subtraction of the weight of the core. Identification of core model and retrieval of weight by means of a bar-code label is chosen, together with computer-based calculation. This invites the introduction of the equipment for use directly in the individual sales transaction. The bar-code solution of roll core identification invites improved customer service by a simultaneous identification of material by the bar-code and a print-out of instructions of use on the bill. At the same time, computer recording of sales transactions in a centralized database opens up for a more optimal stock administration, and more rapid adjustment of the distribution of items to the individual shops to the changes in customer preferences. 
This example illustrates how a design task, initially formulated as a classical function-form transformation problem, from ideas initiated in some detailed design choices, propagates from consideration of the local, specialized function of the separate equipment, through consideration of a more general adaptation of its function to the application context until, finally, the changes in the commercial strategies of the company are considered. A design task formulated in rather specific function-form terms evolves into a much more complex discussion of basic company strategies, involving specialists in trade and organization.

\section{MODELS OF DESIGN}

The conclusions of the discussion of these examples are reviewed in the following points:

Procedural Models of Design. As mentioned in the introduction, and stressed by Hubka (1984): "The predominant Centre of interest in recent design research has been the generation of general procedural models. This may be seen from the many models that have been published." The examples above, however, show clearly that the sequence of decisions taken during an actual design task cannot be represented by a well-ordered sequence progressing from problem formulation to solution. Instead, the framework suggested above seems to be much more realistic, with the separate representation of the entire knowledge-domain and the decision strategies and heuristics guiding navigation in the domain. The procedural models represent design as an orderly process of "transforming the information of a customer's statement of requirements to a full description of the proposed technical system," see figure 4 . Such models separate and isolate the function/form transformation from the much wider design context represented by the example from design of a telephone cable joint in figure 3.

The rationale for this focus of research can be explained in several ways. First of all, modelling activities by task procedures formulated in terms of a sequence of acts on work items is in accordance with the behavioristic tradition which is compatible with natural science and engineering traditions. Furthermore, models in terms of rational, normative task procedures in a different engineering contexts are well suited for teaching in the established engineering schools. The limited domain included in the models is compatible with the curriculum of a university course. However, the normative procedure can be a useful way to introduce novices into the rational and analytical tools of the profession; such procedures are well suited to initialize newcomers who will subsequently be able to adapt to the work context and develop their individual heuristics and collect the tricks of the trade. For design of information systems suited to support experts as well as novices, the examples given clearly show that normative models representing an orderly transformation of well-formed functional specifications into a physical implementation, will not be acceptable.

Representation of the Work Domain of Design. Design of information systems for support of integrated manufacturing requires compatible representations of the various parts of the entire work domain. The examples given clearly illustrate that engineering design is characteristic by iteration among several different domains, which are known only insufficient detail by different individuals, normally with different professional background. Since design is a search "for some kind of harmony between two intangibles: a form which we have not yet designed and a context which we cannot properly describe" (Alexander, 1964), a design task will begin with a mutual exploration of context by the members of the group involved in the functional specification. A similar experience has recently been described by Buciarelli (1984) 
from an ethnographic study in a design team: "The task of design is then as much a matter of getting different people to share a common perspective, to agree on the most significant issues, and to shape consensus on what must be done next, as it is a matter of concept formation, evaluation of alternatives, costing and sizing - all the things we teach." In a later study, Buciarelli elaborates on this point of view, introducing the concept of "object world" to point to the world within which the individual engages the design; a concept which is similar to the 'domains' of the trajectories in our study. He also has identified the need for iteration between different domains: In the design of security equipment for airports, it is necessary to consider the items to look for both from a terrorist strategy point of view and from the detection point of view. The difficulty in detection of 'explosives' by x-rays, as specified, disappears when consideration of the terrorist context and means is re-formulated to detection of 'bombs' because of the necessary wires and switches. This he calls the 'naming discourse': "The invention of a name for a part of the design, for a piece of the action, is designing." 
Figure 4. An example of the classical "spiral model" of the design process representing an orderly descend from the functional specification to the material implementation. It is well suited to serve the introduction of novices in the art of design, but not particularly useful for support systems design. Reproduced from Hubka, 1980.

This problem of iteration between the object worlds of different individuals is not treated in the normal design modelling approaches in any great detail. In a way, the problem is circumvented by perceiving the design process having distinct phases: the design process (feasibility study, preliminary design, detailed design) and the production-consumption cycles (planning for production, distribution, and consumption) which are considered separately: "generally, a new phase is not begun until the preceding one has been completed, although some finer details have to be attended to, while the next phase is in progress." Asimov (1962). This approach probably reflects the way a product design moves through different organizational units of an organization as well as the interest of different research teams. It will, however, not be an acceptable view in integrated system development. A beginning integration is found in the recent development of expert systems attempting to give designers access to information about manufacturing processes and constraints (Alting, 1988). There is, however, a long way to go for design of information systems that can serve to integrate the access to the different 'object worlds' of the examples we have studied. In such a system, integration is not a question of compatible data-bases and computer system, it is a fundamental problem of formatting knowledge-base content according to the search questions of the designer, of supporting the open-ended 'naming discourse.'

Design strategies. From the examples given, it is clear that the design process is by no means a well ordered progression from a problem formulation to the implementation of a solution. Neither is it a conscious, rationally planned process. It can be a rational, conscious process, as when novices follows the procedures learned in courses or a skilled designer evaluates a design and checks it for consistency. However, the actual, creative phases of expert designers' work depend very much on intuition and experience. Hillier et al. (1973), discussing architectural design, call this intuitive basis the designer's 'prestructure' when they argue that the rational process models of design are ineffective because "The syncretic generation of outline solutions in the early stages of design is made to appear illegitimate and undesirable on the grounds that any 'rational' procedure to design must seek to generate the solutions as far as possible from analysis and synthesis of problem information and constraints." -- "The designer's prestructures are not at all an undesirable epiphenomenon, but the very basis of design. Without prestructures of a fairly comprehensible order, it is not possible to identify the existence of a problem, let alone solve it."

The view that intuition and subconscious processes are important for creativity and discovery, has long roots. The mathematician and philosopher Poincare is the source of several classic anecdotes describing the importance of subconscious processes in discovery. His argument is that scientific discovery depends on new combination of known ideas. Since, however, an infinite number of possible combinations exists, discovery depend basically on selection: "Discovery, as I have said, is selection. But this is perhaps not quite the right word. It suggests a purchaser who has been shown a large number of samples, and examines them one after the other in order to make his selection. In our case the samples would be so numerous that the whole life would not give sufficient time to examine them. Things do not happen this way. Unfruitful combinations do not so much as present themselves to the mind of the discoverer" (1904). However, "sudden inspiration never happen except after some days 
of voluntary effort which has appeared absolutely fruitless and whence nothing good seems to have come, where the way taken seems totally astray. These efforts then have not been as sterile as one thinks. They have set going the unconscious machines and without them it would have not have moved and would have produced nothing." This resembles rather closely our perception of the creative phases of design from the discussions with expert designers. Later, another French mathematician, Hadamard (1945), elaborates on Poincare's discussion and describes four phases of creative discovery: 1.) preparation, which involves a conscious exploration of available ideas and concepts, 2.) incubation, "no work of the mind is consciously perceived," but something is happening which, at a later instant result in 3.) illumination when ideas emerge and, require to be 4.) precised and evaluated. Precision and evaluation are the only parts of the design process which are suited for the normative procedure formulation. For design of information system, however, the preparation phase with the 'object world' exploration is just as important. The mental processes of this phase can be compared to the browsing in a shop or library when you realize, you have a problem or need which you cannot make explicit. Support of this process can only be realized, if a recognizable structure can be defined for the space to be explored. In a library, you expect a certain structure in the arrangement of the books on the shelves. Similarly, a structure to the knowledge-bases should be established that will enable the transfer of search heuristics among different 'object worlds'. This is precisely what is intended with the part-whole / means-ends map discussed in the previous section. If an identical structure can be imposed on the different object worlds, the initial exploration and 'naming' in a design team will be facilitated and, if knowledge-bases of the different domains are organized according to one uniform structure, use of integrated information system will be possible. The structure of the part-whole / means-ends map lend itself to use of a spatial analogy of the knowledge base which will support memory and exploring browsing. (The use of a spatial arrangement of items to remember is a classical mnemotechnical trick, suggested by Semonides' (500 B.C.) who imagined items to be placed around in a room or street familiar to him). In order to index knowledge items such that they can be retrieved from different points of view in the naming game, they should be retrievable from terms related to what they are, why they may be useful and what they can be used for, and how they are implemented, as it was discussed in the previous section (Rasmussen and Pejtersen, 1987; Pejtersen, 1988).

This means-ends structure is, at present, implicit in several approaches to structuring design models in the form of more limited function-form considerations. Alexander (1964), states that "every form can be described in two ways: from the point of view of what it is, and from the point of view of what it does." Hubka's normative modelling of the design procedure is based on an "abstraction and classification of technical systems" which is a direct transfer of the biological function - form distinction in terms of Phylum and Class for general functional properties, Genus for internal function structure, and Family for anatomical structure. It appears, however, that this conceptual development has been constrained by its origin in a biological terminology not including intentions and purpose which are indispensable for a design framework.

Models of Work Organization. As it turns out, even if a design task is presented as a classical function-form design problem, it can readily turn out to require a careful analysis of the changes which are likely to propagate through the organization receiving the result of the design effort. The staff will adapt to potential benefits as well as to the constraints presented by any new tool and the result will be changes of the role allocation of the staff members, whether or not it is planned by management. The actual organization of work will adapt to the new situation in an attempt to match 
requirements with resources, competency, and interest of individual agents. In addition, if advanced information systems are introduced, they will support some and constrain other modes of communication among staff members. This, in turn will influence the structure of the informal social organization. A particular problem to have in mind is the importance of communication of intentions and values for effective planning, for reliable interpretation of ambiguous messages, and for the opportunity for error recovery. At present, information systems are not particularly well geared to communicate this kind of information, which is normally only implicitly present. This discussion leads to the conclusion that for design of equipment and systems for modern integrated and tightly coupled work organizations, predictive models representing the adaptive, informal role allocation and social organization are very important. By recursion, these considerations also apply to the design of advanced information systems and work stations for design and production planning in integrated manufacturing systems.

Unfortunately, most of the present models of decision making in organizations do not support this need. In general, decision making has been analyzed and modelled in terms of isolated 'decisions' made by one person. In reality, however, decision making is a continuous, inter-personal process aiming at dynamic control of the state of affairs in a work domain and several decision makers typically will co-operate in this control.

Furthermore, decision making in social groups usually has been studied in a very focused manner either from the economic, the management, or the sociological point of view, very often resulting in formal, normative models. Present literature on organizations gives considerable attention to the economic criteria, "but hides the importance of the instrumental question, which in fact take priority" (Thompson, 1967). What is urgently needed for analysis of the implications of modern information technology is a cognitive approach to models of distributed decision making in actual, complex work settings. This is a topic which is now rapidly attracting the attention for research programs (See Rasmussen et al. 1988). For development of predictive models of work organizations it is very important to consider the fact, also discussed in detail by Thompson, that "the technical parts of the system provide a major orientation for the social structure. There are both instrumental and economic reasons but the instrumental question is prior to that of efficiency." This point of view is readily compatible with the modelling approach discussed in the introduction (Figure 2), which lead to the a systems control point of view according to which decision making and social organization cannot be modelled separately but, in stead, the organization evolves in a group of cooperating agents striving to control the state of affairs in a work environment in a concerted way.

\section{CONCLUSION}

The conclusion of the present discussion is that the development of integrated systems cannot be based on a bottom-up coordination of tools and systems which are designed separately, but will require consideration of the function of the total system, including the organizational aspects.

\section{ACKNOWLEDGMENT.}

Discussion of actual design cases with Johan Gregersen and Michael Muller, IPU, Technical University and their kind support in the analysis is gratefully acknowledged. 
The research has been supported by a grant from the Danish Technical Research Council.

\section{REFERENCES.}

Alexander, C. (1964). Notes on the Synthesis of Form. Cambridge, MA: Harvard University Press.

Asimov, Morris (1962): Introduction to design. Englewood Cliffs, N.J.: Prentice Hall.

Bohn, R. E., and Jaikumar, R. (1986): Re-Examining the Use of Artificial Intelligence in Manufacturing. Proceedings of the 1986 IEEE International Conference on Systems, Man, and Cybernetics, Vol. 1, pp. 834-839

Bucciarelli, L.L. (1984): Reflective Practice in Engineering Design. Design Studies, Vol. 5, No. 3, July 1984.

Bucciarelli, L. L. (1988): An Ethnographic Perspective on Engineering Design. Design Studies, Vol. 9, No. 3, July 1988, pp.159-168.

Hadamard, J. L. (1945). The Psychology of Invention in the Mathematical Field. Princeton: Princeton University Press.

Hillier, B. and Leaman, A., (1973): How is Design Possible? A Sketch for a Theory. DMG-DRS Journal Vol. 8, No. 1, pp.40-50.

Hubka, V. (1980): Principles of Engineering Design. London: Butterworth Scientific.

Lenau, T., and Alting, L. (1988): Artificial Intelligence for Process Selection. CIRP International Seminar on New Manufacturing Technology, Singapore, August 1988.

Pejtersen, A.M., (1988): Beyond the Desk Top Metaphor: Information Retrieval With an Icon Based Interface. 7th International Workshop on Informatics and Psychology, Scharding Austria, 1988; To be Published.

Pejtersen, A. M. and Rasmussen, J., Information Retrieval in Integrated Work Stations. Invited Paper, International Conference on Information and Knowledge, Kanagawa University, Yokohama: November, 1987.

Poincare, H.: Science and Method. Book I: The Scientist and Science. Translated by Francis Maitland, Dover Publications.

Rasmussen, J. (1986). Information Processing and Human Machine Interaction: An Approach to Cognitive Engineering. New York: North Holland.

Rasmussen, J.(1988): A Cognitive Engineering Approach to the Modelling of Decision Making and Its Organization in Process Control, Emergency Management, CAD/CAM, Office Systems, Library Systems. In: W. B. Rouse (Ed.): Advances in Man-Machine System Research, Vol. 4, J.A.I. Press Inc.

Rasmussen, J., Brehmer, B. and Leplat, J. (Eds. 1988): New Technology and Distributed Decision Making, London: Wiley. In Press

Simon, H. A. (1969). The Sciences of the Artificial. Cambridge, Ma: M.I.T. Press.

Thompson, J.D. (1967): Organizations in Actions. New York: McGraw-Hill. 